\title{
Prevalence of neck pain among the undergraduate physical therapy students of university of Balochistan, Quetta, Pakistan
}

\author{
ISSN: $2455-5487$
}

DOI: https://dx.doi.org/10.17352/jnppr

Received: 14 July, 2021

Accepted: 29 July, 2021

Published: 30 July, 2021

*Corresponding author: Dr. Aadil Ameer Ali, Lecturer Physiotherapy, Institute of Physiotherapy \& Rehabilitation Sciences, Shaheed Mohtarma Benazir Bhutto Medical University, Larkana, Pakistan, Tel: +923002929464; E-mail: aadilamirali@hotmail.com

Keywords: Neck pain prevalence; Physical therapy students; University of Balochistan Quetta; Pakistan https://www.peertechzpublications.com

Check for updates

\section{Shivum Sachdev' ${ }^{1}$, Sakshi Talreja', Ibtahaj-ul-islam Ansari', Sidra Nasir ${ }^{1}$ and Aadil Ameer Ali ${ }^{2 *}$ \\ 'Department of Physiotherapy, Faculty of Pharmacy \& Health Sciences, University of Balochistan, Quetta, Pakistan \\ ${ }^{2}$ Institute of Physiotherapy \& Rehabilitation Sciences, Shaheed Mohtarma Benazir Bhutto Medical University, Larkana, Pakistan}

\begin{abstract}
Objective: To assess the prevalence of pain among the undergraduate physical therapy students of university of Balochistan, Quetta.

Material \& method: A cross sectional study was carried out among the 158 participants who were enrolled in department of Physical Therapy, University of Balochistan, Quetta. The participants were requested to answer the self-developed questionnaire consists of different questions (demographics \& onset of pain). The collected data was analyzed by using statistical package of social sciences (Spss) version 21.

Results: The Majority ( $n=101,63.9 \%)$ of the participants were from the age group of 18 to 22 years and $(n=91,57.6 \%)$ were female. Whereas in marital status mostly $(n=147,93 \%)$ of the participants were un-married. Majority $(n=49,31 \%)$ of the participants were the enrolled in the 1st professional year. After checking their working status $(n=144,91.1 \%)$ were not doing any job, whereas $(n=131,82.9 \%)$ of the participants were not taking any medicines for the management of neck pain. In the onset of pain $(n=109,68.9 \%)$ of the participants reported the occasional onset of pain followed by the $(n=21,13.3 \%)$ frequent pain.
\end{abstract}

Conclusion: The study concludes that the prevalence of neck pain among the undergraduate physical therapy students of university of Balochistan was high and measured about $69 \%$.

\section{Introduction}

Neck pain is a typical however significant musculoskeletal problem in present day culture nowadays, with revealed 1-year prevalence in the total populace shifting from $16.7 \%$ to $75.1 \%$ for adults [1]. The Global Burden of Disease (GBD) 2017 reported that the musculoskeletal conditions are to be the second highest contributor of Global Disability [2]. Neck pain prevalence is high among undergraduate students, however the prevalence of neck pain in highest among physiotherapy and nursing students [3]. Approximately 30\% of people with neck pain faces the restrictions in their activities of daily living [4]. There are multiple evidences available, suggesting that patients with neck pain have reduced maximal isometric neck strength and endurance capacity [5-8]. There are many different causes of neck pain such as trauma, infections or inflammatory conditions, rheumatic disorders, and congenital diseases however, most often no particular reason can be found, and the condition is marked as non-specific neck pain [9]. History of previous neck pain, academic stress, smart phone and laptop use, senior years of study, anxiety and tall height are some of the risk factors associated with neck pain among undergraduate students $[2,3]$. Neck pain is more common among females as compared to males $[1,10]$. The Patient's 
history and examination are significant in distinctive likely causes and identifying red flags. The Physiotherapists and other health care providers examine patient's active cervical range of motion to assess the levels of impairments as well as to measure treatment outcomes Some of the practitioners also assess passive cervical range of motion and palpation procedures, however these reviews conclude poor methodological quality [11-15]. The clinical history and assessment of patients with neck pain direct the appropriate timing and choice of diagnostic investigations such as plain radiography, MRI, and myelography with CT [16]. Diagnostic imaging should be ordered only when necessary because of the high incidence of asymptomatic radiographic abnormalities [11]. Individuals having a habitt of adopting same posture for prolong time can be the leading factors and contributors I developing the pain in neck region so its important to check the status of neck pain among the students.

\section{Material and methods}

\section{Study design, settings and duration}

A cross sectional descriptive study was conducted from June to August 2018, and data was collected from the undergraduate students of Department of Physiotherapy , university of Balochistan, Quetta, Pakistan.

\section{Sampling}

Convenient Non-Probability Sampling Technique among the 158 selected participants were used. Participants with both genders (male \& female), suffering from neck pain and willing to participate were included in the study. While, patient with a previous history of any surgical intervention, with any pathology, with any malignancy, with fracture with central nervous system alteration and not willing to sign inform consent were excluded.

\section{Data collection tool}

A self-constructed proforma was used to collect the data, which include the demographic Characterstics age, gender, marital status, educational year, working status and use of medicines. While, the included disease Characterstics were the occurrence of pain (No pain, frequently, occasionally or constantly).

\section{Data collection procedure}

The participants were asked to fill the questionnaire on the spot, only the minor help were given upon the request of participants in order to understand the questionnaire.

\section{Data analysis procedure}

Descriptive statistics; categorical variables were measured as frequency and percentage. Data was analyzed by using Statistical Package for Social Sciences (SPSS) version 23.

\section{Ethical concern}

As the approval was taken from the ethical review committee of Department of physiotherapy, Faculty of Pharmacy \&
Health Sciences, University of Balochistan, Quetta, Pakistan. Informed consent was taken from participants containing that their participation is voluntary, their information will be kept confidential and anytime they can leave the study, after that the proforma was filled for data collection.

\section{Results}

\section{Demographic characteristics}

Table 1 displays demographic characteristics of participants. Most ( $n=101,63.9 \%$ ) of the participants were having age of 18 22 years and were females $(n=91,57.6 \%)$. In marital status most $(\mathrm{n}=147,93.0 \%)$ of the participants were unmarried and $(\mathrm{n}=49,31.0 \%)$ were studying in first semester. Most of the after checking the working status majority $(n=144,91.0 \%)$ of respondents were not doing any job/ not working.

\section{Intake of medications.}

Figure 1 displays intake of medication for neck pain by participants. Most of the participants $(n=131,82.9 \%)$ were not taking any medications for managing the neck pain.

\section{Occurrence of neck pain}

Table 2 displays occurrence of neck pain reported by participants. Most $(n=109,69.0 \%)$ of the participant reported that felt neck pain occasionally, followed $(n=21,13.3 \%)$ by frequent neck pain.

\section{Percentage of participants having neck pain}

Figure 2 displays percentage of participants having neck pain. $69 \%$ of participants reported that they are suffering from neck pain.

\begin{tabular}{|c|c|c|}
\hline Demographic Characteristics & Frequency ( $n=158$ ) & $\begin{array}{l}\text { Percentage } \\
(\%=100.0)\end{array}$ \\
\hline \multicolumn{3}{|l|}{ Age group } \\
\hline $18-22$ years & 101 & 63.9 \\
\hline 23-27years & 57 & 36.1 \\
\hline \multicolumn{3}{|l|}{ Gender } \\
\hline Male & 67 & 42.4 \\
\hline Female & 91 & 57.6 \\
\hline \multicolumn{3}{|l|}{ Marital status } \\
\hline Married & 11 & 07 \\
\hline Unmarried & 147 & 93 \\
\hline \multicolumn{3}{|c|}{ Education } \\
\hline $1^{\text {st }}$ Professional & 49 & 31 \\
\hline $2^{\text {nd }}$ Professional & 20 & 12.7 \\
\hline $3^{\text {rd }}$ Professional & 16 & 10.1 \\
\hline $4^{\text {th }}$ Professional & 41 & 25.9 \\
\hline $5^{\text {th }}$ Professional & 32 & 20.3 \\
\hline \multicolumn{3}{|c|}{ Working status } \\
\hline Working/ Doing job & 18 & 8.9 \\
\hline Not working & 144 & 91.1 \\
\hline
\end{tabular}

Citation: Sachdev S, Talreja S, Ansari IUI, Nasir S, Ali AA (2021) Prevalence of neck pain among the undergraduate physical therapy students of university of Balochistan, Quetta, Pakistan. J Nov Physiother Phys Rehabil 8(1): 020-023. DOI: https://dx.doi.org/10.17352/2455-5487.000088 


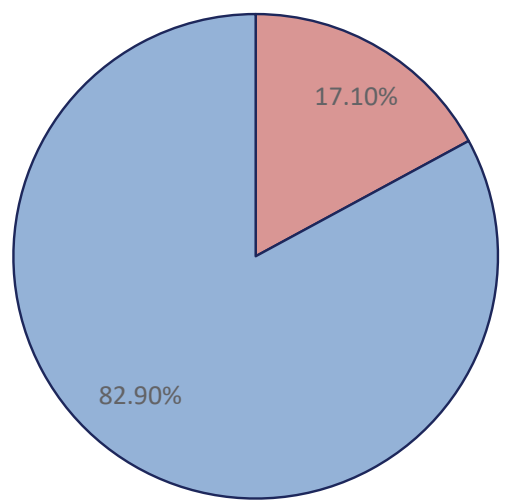

$\square$ Yes $\square$ No

Figure 1: Intake of medications for neck pain.

Table 2: Occurrence of Neck Pain.

\begin{tabular}{|c|c|c|}
\hline Pain Pattern & $\begin{array}{c}\text { Frequency } \\
(\mathbf{n = 1 5 8 )}\end{array}$ & $\begin{array}{c}\text { Percentage } \\
(\%=100.0)\end{array}$ \\
\hline No pain & 10 & 6.32 \\
\hline Occasionally & 109 & 68.9 \\
\hline Frequently & 21 & 13.3 \\
\hline Constantly & 18 & 11.4 \\
\hline
\end{tabular}

\section{Participants Having Neck Pain.}

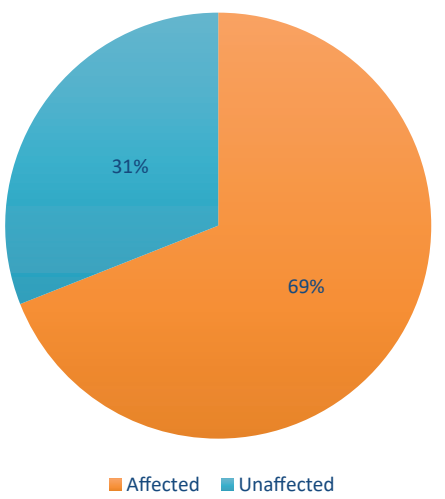

Figure 2: Percentage of participants having neck pain.

\section{Discussion}

The results of present study concludes that $69 \%$ of undergraduate students of university of Balochistan Quetta, Pakistan were suffering from neck pain. This finding is consistent with similar studies reporting higher rates of neck pain occurrence in undergraduate students, conducted in China with (45.0\%) [3], India with (58.3\%) [17], Ethiopia with $(49.2 \%)$ [18], Pakistan with (44.8\%) [19], Australia with (52.8\%) [20], USA with (35\%) [21], Iran with (39.4\%) [22], Brazil with (35.69\%) [23], Malaysia with (41.8\%) [24] and in Thailand it was (46\%) [25].

In Previous conducted studies, the reported reasons that makes undergraduate students prone to develop the neck pain were the usual Lack of physical activity, the stress related to studies, and universal adoption of different digital gadgets make the undergraduate students prone to develop musculoskeletal pain-related issues specially in the neck region [17]. Another study claimed that neck pain among the undergraduates were associated with anxiety, low back pain, tall stature and prolonged smart phone usage [3]. Pratek bahera reported that joining the Graduate level studies is found one of the leading cause for neck pain and it's also directly associated with high risk of pain in different regions especially in back as well. He further suggested that psychological burden during study years causes neck pain, while the over burden and prolong siting in same posture were found the most aggravating factors for neck pain. It's also stated that the neck pain leads to reduction in neck range of motion in most of the directions [17]. Furthermore, poor adopted posture during study hours was found causative agent for neck pain among the undergraduate students $[26,27]$.

\section{Conclusion}

The study concludes that the prevalence of neck pain was $69 \%$ among the undergraduate physical therapy students of university of Balochistan, Quetta, Pakistan.

\section{Recommendations}

The study was conducted among the undergraduate students of physical therapy. In future the studies should be conducted in other departments in detail as well, in order to analyze the factors and predictors of neck pain.

\section{Limitations}

The study was conducted among the under graduate physical therapy student only, in future the study should be conducted in other departments as well. In this study few demographics like smoking and Body mass index which are highly contributing factors in neck pain were not asked, the next studies they should be added.

\section{Acknowledgements}

We acknowledge the support of participants who volunteered themselves for data collection.

\section{Author contributions}

All authors contributed equally.

\section{References}

1. Fejer R, Kyvik KO, Hartvigsen J (2006) The prevalence of neck pain in the world population: a systematic critical review of the literature. Eur Spine J 15: 834848. Link: https://bit.ly/3zMm0DL

2. Global, regional, and national incidence, prevalence, and years lived with disability for 354 diseases and injuries for 195 countries and territories, 19902017: a systematic analysis for the Global Burden of Disease Study 2017. Lancet 392: 1789-1858.

3. Chan LLY, Wong AYL, Wang MH, Cheung K, Samartzis D (2020) The prevalence of neck pain and associated risk factors among undergraduate students: A large-scale cross-sectional study. International Journal of Industrial Ergonomics 76: 102934. Link: https://bit.ly/3I7bAdS 
4. Picavet HSJ, Schouten JSAG (2003) Musculoskeletal pain in the Netherlands: prevalences, consequences and risk groups, the DMC3-study. Pain 102: 167178. Link: https://bit.ly/3lcivT5

5. Barton PM, Hayes KC (1996) Neck Flexor Muscle Strength, Efficiency, and Relaxation Times in Normal Subjects and Subjects With Unilateral Neck Pain and Headache. Arch Phys Med Rehabil 77: 680-687. Link: https://bit.ly/3I7CulL

6. Chiu TTW, Lo SK (2002) Evaluation of cervical range of motion and isometric neck muscle strength: reliability and validity. Clin Rehabil 16: 851-858. Link: https://bit.ly/3i6lcCG

7. Jull G, Kristjansson E, Dall'Alba P (2004) Impairment in the cervical flexors: a comparison of whiplash and insidious onset neck pain patients. Man The 9 : 89-94. Link: https://bit.ly/3iRQQny

8. Lee H, Nicholson LL, Adams RD (2005) Neck Muscle Endurance, Self-Report, and Range of Motion Data From Subjects With Treated and Untreated Neck Pain. J Manipulative Physiol Ther 28: 25-32. Link: https://bit.ly/3ybUcsj

9. Bogduk N (1984) Neck pain. Aust Fam Physician 13: 26-30. Link: https://bit.ly/3zMmjyp

10. Bot SDM, van der Waal JM, Terwee CB, van der Windt DAWM, Schellevis $F G$, et al. (2005) Incidence and prevalence of complaints of the neck and upper extremity in general practice. Ann Rheum Dis 64: 118-123. Link: https://bit.ly/3rJMqDA

11. Douglass AB, Bope ET (2004) Evaluation and Treatment of Posterior Neck Pain in Family Practice. J Am Board Fam Pract 17. Link: https://bit.ly/3xcr8zW

12. Cleland JA, Childs JD, Fritz JM, Whitman JM (2006) Interrater reliability of the history and physical examination in patients with mechanical neck pain. Arch Phys Med Rehabil 87: 1388-1395. Link: https://bit.ly/3zOb6xi

13. Seffinger MA, Najm WI, Mishra SI, Adams A, Dickerson VM, et al. (2004) Reliability of spinal palpation for diagnosis of back and neck pain: a systematic review of the literature. Spine (Phila Pa 1976) 29: E413- E425. Link: https://bit.ly/3rHU7d

14. Stochkendahl MJ, Christensen HW, Hartvigsen J, Vach W, Haas M, et al (2006) Manual examination of the spine: a systematic critical literature review of reproducibility. J Manipulative Physiol Ther 29: 475-485. 85.e1-10. Link: https://bit.ly/3j3cbGh

15. van Trijffel E, Anderegg Q, Bossuyt PM, Lucas C (2005) Inter-examiner reliability of passive assessment of intervertebral motion in the cervical and lumbar spine: a systematic review. Man Ther 10: 256-269. Link: https://bit.ly/3jfQMP1

16. Boyce RH, Wang JC (2003) Evaluation of neck pain, radiculopathy, and myelopathy: imaging, conservative treatment, and surgical indications. Instr Course Lect 52: 489-495. Link: https://bit.ly/3B068mh

17. Behera P, Majumdar A, Revadi G, Santoshi JA, Nagar V, et al. (2020) Neck pain among undergraduate medical students in a premier institute of central India: A cross-sectional study of prevalence and associated factors. J Family Med Prim Care 9: 3574-3581. Link: https://bit.ly/2TMdSnC

18. Weleslassie GG, Meles HG, Haile TG, Hagos GK (2020) Burden of neck pain among medical students in Ethiopia. BMC Musculoskeletal Disorders 21: 14. Link: https://bit.ly/3ye5trQ

19. Ayaz SB, Malik R, Khan AA, Gill ZA, Akhtar N, et al. (2016) Intensity of neck pain secondary to excessive flexion posturing, its association with study activities and duration of posturing and impact on sleep in students of women medical college, abbottabad. Pak Armed Medical Journal. Link: https://bit.ly/3i7Maea
20. Smith DR, Leggat PA (2007) Prevalence and Distribution of Musculoskeleta Pain Among Australian Medical Students. Journal of Musculoskeletal Pain 15 39-46. Link: https://bit.ly/3l8VNeM

21. Du JY, Aichmair A, Schroeder JE, Kiely PD, Nguyen JT, et al. (2017) Neck Pain and Low Back Pain in Medical Students: A Cross-Sectional Study. International Archives Public Health Community Medicine 1: 002. Link: https://bit.ly/3rHUd4H

22. Sadat BE, Ghazani AB, Azizi R, Parizad M (2013) Prevalence and Risk Factors of Neck and Shoulder Pain in Medical Students of Tabriz University of Medical Sciences. Med J Tabriz Uni Med Sciences Health Services 35: 12-17. Link: https://bit.ly/3rGBwhB

23. Silva AL, Smaidi K, Rovani Pires MH, Pires OC (2017) Prevalence of chronic pain and associated factors among medical students. Rev Dor São Paulo 18 108-111. Link: https://bit.ly/3ycbJR0

24. Alshagga MA, Nimer AR, Yan LP, Ibrahim IAA, Al-Ghamdi SS, et al. (2013) Prevalence and factors associated with neck, shoulder and low back pains among medical students in a Malaysian Medical College. BMC Research Notes 6: 244. Link: https://bit.ly/375Tel8

25. Kanchanomai S, Janwantanakul P, Pensri P, Jiamjarasrangsi W (2011) Risk factors for the onset and persistence of neck pain in undergraduate students: 1-year prospective cohort study. BMC Public Health 11: 566. Link: https://bit.ly/3l8VVeg

26. Amjad B, Paracha S, Iqbal M, Masood K, Mughal S, et al. (2019) Prevalence of Neck Pain and Its Different Associated Factors Among Undergraduate Students of Sargodha Medical College. Journal of Yoga And Physiotherapy 8 : 555731. Link: https://bit.ly/3f67aA6

27. Santoshi JA, Jain S, Popalwar HJ, Pakhare AP (2019) Musculoskeletal disorders and associated risk factors in coaching students: A cross-sectional study. J Family Med Prim Care 8: 929-933. Link: https://bit.ly/3xfVfWG

\section{Discover a bigger Impact and Visibility of your article publication with}

\section{Peertechz Publications}

\section{Highlights}

* Signatory publisher of ORCID

* Signatory Publisher of DORA (San Francisco Declaration on Research Assessment)

- Articles archived in worlds' renowned service providers such as Portico, CNKI, AGRIS, TDNet, Base (Bielefeld University Library), CrossRef, Scilit, J-Gate etc.

* Journals indexed in ICMJE, SHERPA/ROMEO, Google Scholar etc.

* OAI-PMH (Open Archives Initiative Protocol for Metadata Harvesting)

* Dedicated Editorial Board for every journa

* Accurate and rapid peer-review process

* Increased citations of published articles through promotions

* Reduced timeline for article publication

Submit your articles and experience a new surge in publication services (https://www.peertechz.com/submission).

Peertechz journals wishes everlasting success in your every endeavours.

Copyright: @ 2021 Sachdev S, et al. This is an open-access article distributed under the terms of the Creative Commons Attribution License, which permits unrestricted use distribution, and reproduction in any medium, provided the original author and source are credited.

Citation: Sachdev S, Talreja S, Ansari IUI, Nasir S, Ali AA (2021) Prevalence of neck pain among the undergraduate physical therapy students of university of Balochistan, Quetta, Pakistan. J Nov Physiother Phys Rehabil 8(1): 020-023. DOI: https://dx.doi.org/10.17352/2455-5487.000088 